Industrial Marketing Management

Special issue on: Power in business, customer, and market relationships

\title{
The current situation and future conceptualization of power in industrial markets
}

\author{
Martin Hingley, University of Lincoln, $\mathrm{UK}^{1}$ \\ Rob Angell, University of Cardiff, UK \\ Adam Lindgreen, University of Cardiff, UK
}

\footnotetext{
${ }^{1}$ Professor Martin Hingley, Lincoln Business School, University of Lincoln, Brayford Pool, Lincoln LN6 7TS, UK. E-mail: mhingley@lincoln.ac.uk Tel: +44 (0)1522 835683. For all correspondence.

Dr. Rob Angell and Professor Adam Lindgreen, Cardiff Business School, Cardiff University, Aberconway Building, Colum Drive, Cardiff CF10 3EU, U.K. E-mail: AngellRJ@ cardiff.ac.uk LindgreenA@cardiff.ac.uk
} 


\section{Biographies}

Martin Hingley is Professor of Strategic Marketing at Lincoln Business School, University of Lincoln, UK. His current research interests focus on marketing and supply chain management, power in interfirm and network relations, the interface of marketing and purchasing, and local and regional network marketing. He has published in Industrial Marketing Management, Journal of Marketing Management, Supply Chain Management: An International Journal, and Entrepreneurship and Regional Development.

Rob Angell is Lecturer in Marketing Research. His areas of research interest are food marketing and sports sponsorship. His recent work has been published in Industrial Marketing Management, European Journal of Marketing, Journal of Business Research, and Journal of Advertising Research.

Adam Lindgreen is Professor of Marketing and Head of Marketing and Strategy at Cardiff Business School, University of Cardiff, UK. His current research interests include business and industrial marketing, experiential marketing, and corporate social responsibility. His recent publications have appeared in California Management Review, Journal of Business Ethics, Journal of the Academy of Marketing Science, Journal of Product Innovation Management, and Journal of World Business. 


\section{Research Highlights}

- This concluding paper draws together current themes related to power in business, customer, and market relationships.

- The evaluations of the contributions to this special issue seek to rationalize the context of power, from its origins and contributions to the story, current theory, and practice of power in industrial markets.

- Future directions for the theory and practice of power in business markets are postulated. 


\title{
The current situation and future conceptualization of power in industrial markets
}

\begin{abstract}
This article offers overview of research on power in industrial and business markets, conducted through the 10 articles in the special issue. These contributions are catalysts for defining the history, context, current situations, and future developments and prospects for power in the business world. Therefore, this article presents a conceptualization and understanding of power, using the special issue as a lens through which to view past antecedents, present understanding, and future directions. In addition to studies that mine past and present academic and practical rationales for power, the empirically based contributions test and explore power. This article identifies and thematically draws out and labels the principal manifestations across these contributions, to link origins with current principal foci and identify the most likely emphases of theory and practice for the future business-tobusiness arena.
\end{abstract}

Keywords: power, industrial marketing, business marketing, theory, practice. 


\section{Introduction}

As a concept relevant to the theory and practice of business, power has great importance and thus has attracted substantial attention from business academics, though with somewhat patchy coverage. Considerable early research came from industrial marketers who focused on reapplications of theory derived from interpersonal human relations (e.g., Emerson, 1962; French \& Raven, 1959; Thibaut \& Kelly, 1959), such that they defined power according to human interactions and applied it to business exchanges. For example, researchers interested in industrial markets and the influence of power in interfirm exchanges, who adopted the views of the Industrial Marketing and Purchasing Group (IMP), modelled power with an interactionist framework; featuring dyadic, and then network interactions. Industrial Marketing Management (IMM) was then and remains at the forefront of defining, interpreting, and developing knowledge about power in business contexts and has constituted the forum for advanced thought on the subject.

In 2005, IMM had an instrumental role in setting the research agenda: In Volume 34, Issue 8, it departed from traditional approaches and published a contribution that challenged the generally accepted preconceptions of a negative view of power. That is, asymmetry had been regarded as unacceptable, unworkable, or just plain wrong, according to an idealistic objection to coercive power plays. However, Hingley (2005a) shone a new light on power, revealing it to be not some toxic alien force but rather a constant presence, for which asymmetry was acceptable and workable. Hingley also called for a better understanding of power and the motives of the participants in ongoing, relationally fluid, interfirm exchanges. In what became a mini-debate within the issue, Kumar (2005), Naude (2005), and Blois (2005) commented on the contribution, and then Hingley (2005b) responded. Yet even this 
influential volume of IMM did not contain sufficient consideration of power in business. Ten years later, $I M M$ is the appropriate place to revisit power with a fuller treatment.

With this concluding article, we seek to bring the field up to date by providing an overview of current thinking about power, in the context of industrial and business markets, as indicated by the important themes emerging from this special issue. The following 10 articles, with their varying approaches and emphases, draw out several themes that underpin and challenge the conditions and applications of power in business, customer, and market relationships. They collectively address the history and origins of power, its current thematic emphases, and its potential new directions and treatments. We identify the following themes:

1. The analyses of the antecedents of power often hark back to its long-standing, fragmented treatment in both academia and practice. Thus, the first theme to emerge is the pursuit of an understanding of the origins, definitions, interplay, and applications of power in an interpersonal context, and its application to business relations.

2. Authors seek to pin down and define key concepts surrounding power, such as trust and the nature of asymmetry.

3. From the start, industrial marketers have sought to model and measure power in interfirm relations. The third theme thus pertains to the accuracy and appropriateness of measuring power.

4. Most investigations, analyses, and interpretations of power have focused on interfirm exchanges. But, why is our focus drawn to (often dyadic) interfirm exchanges?

5. The study of power often hones in on particular business contexts and circumstances. The final theme involves why certain business sectors and contexts 
(e.g., retailing and food supply) constitute such rich material for researchers seeking to understand power in the business world.

After delineating this theme-based analysis, we suggest some avenues for research that considers power in relation to business, customer, and market relationships. Finally, we bring this issue to a close with some concluding remarks.

\section{Special issue contributions and themes of power}

\section{1. $\quad$ Learning from interpersonal relationships}

The authors whose work appears in this special issue analyze the origins of power from interpersonal perspectives, to define and interpret, as well as measure and model, power. For example, Cowan, Paswan, and Steenburg chart the development of applications of interpersonal power to interfirm settings, invoking the widely cited types of power introduced by French and Raven (1959) (expert, reference, legitimate, reward, and coercive). They also draw inspiration from Yeung, Selen, Zhang, and Huo (2009), regarding coercive and noncoercive power dimensions, to highlight the development of power sources that dominant firms use in coercive and non-coercive ways, to ensure partnership governance that reflects their own interests. Similarly, Marcos-Cuevas, Julkunen, and Gabrielsson draw on Emerson’s (1962) chronicles of power and dependency, from a basis of interpersonal relations. Business researchers often use social exchange theory (Emerson, 1962; Thibaut \& Kelley, 1959), such that it remains a prominent research framework for describing interfirm power. In addition, Kumar (2005) summarizes several definitions of power, including dependence, punitive capability, non-coercive influence strategies, and punitive actions, and refers to the latter as the antithesis of trust in relationships. He asserts that punitive action makes power imbalances intolerable. Trust and commitment (e.g., Mohr \& Spekman, 1994; Ganesan, 1994; Geyskens, 
Steencamp, Scheer \& Kumar 1996) also moderate business relationships, and these concepts are informative for this issue’s contributors (e.g., Chicksand).

\subsection{Understanding and redefining asymmetry}

Most considerations of asymmetry in business relationships define relationship protagonists as "haves" or "have nots," creating a state of imbalance that might be determined by size (Cox, 1999) or other factors, such as channel position or brand leadership. Asymmetry thus appears as a negative, problematic issue for interfirm relations; MarcosCuevas, Julkunen, and Gabrielsson even note that it has been cited as the cause of breakdowns in trust. However, these authors and Munksgaard, Johnsen, and Patterson propose a different view of asymmetry. Marcos-Cuevas, Julkunen, and Gabrielsson note how goal alignment can build trust and moderate asymmetry; Munksgaard, Johnsen, and Patterson consider the influence of goal alignment, but argue that imbalanced exchanges can be subdivided further into two distinct types of asymmetric relationships: product/technology development-oriented asymmetric relationships or complementary competencies-oriented asymmetric relationships. With their empirical work, they determine that small suppliers that actively pursue their self-interest in connection with larger, more powerful buyers realise greater success; the larger buyers recognize the value of joint goal seeking for deriving collective market and profitability benefits.

Such insights reflect the views of Hingley (2005a), Hingley and Lindgreen (2010), Belaya and Hanf (2009), and Easton (2002), who describe how acceptance of asymmetry might lead to workable co-creation, even in an imbalanced state. Munksgaard, Johnsen, and Patterson bring the characteristics of the relationship (presence of trust, cooperation, power dependence) to the fore as moderators; despite the imbalance, smaller, perceivably weaker parties can thrive if they have a self-interested drive (Johnson \& Ford, 2006, 2008) and a 
creativity-based advantage that larger partners/buyers desire. According to Munksgaard, Johnsen, and Patterson, asymmetric relationships often function well, regardless of size imbalance issues, but relationship characteristics can have more detrimental effects, notably as they relate to levels of cooperation.

Cowan, Paswan, and Steenburg, citing Mohr and Spekman, (1994), question the lack of knowledge about the trade-offs firms make (particularly the loss of autonomy) when entering such relationships. They model this detail and argue that partner firms, "especially the weaker ones, may choose to stay in a relationship even when the dominant firm relies on strong and possibly unpleasant influence strategies” (Kumar, 2005, p. 865, in terms of punitive capabilities and actions), “as long as there are still benefits of doing so" (Cox and Chicksand, 2005; Ramsey, 1996; Hingley, 2005a). Cowan, Paswan, and Steenburg thus add valuable understanding about the gradations of asymmetric relationships for defining “exploitative” versus “tolerable” relationships, as well as how weaker parties can (re)position themselves to achieve the tolerable form or even, though rarely, an "ideal” (high commitment and trust, open communication) relationship. Because such ideal relationships are rare, they are prone to disruption by organizations, which naturally seek to secure an inequitable proportion of relationship value for themselves (Cox, 2004).

Such considerations also can be viewed according to a fluid framework of the business environment, in which relationships do not and cannot stay the same (Hingley, 2005b). The issue of relationship fluidity in existing interfirm relationships has tremendous impacts on the conduct and maintenance of asymmetrical relationships. In his empirical work, Chicksand notes that what appear to be identifiable types of relationships can change, and the status of a relationship between, say, nominally interdependent parties, evolves as a result of power to become more buyer or supplier dominant. Von Bockhaven, Mathyssens, and Vandenbempt also believe that weaker parties can reduce the influence of that power 
over them, through the use of "soft power," achieved through alignment rather than enforced interests. In contrast, "hard power" might be expressed by powerful buyers, according to a size-power asymmetry, coercion, or reward control. Soft power instead requires collaborative, cooperative, and trust-based behaviour, without resorting to head-on conflict or coercion.

In their studies, Marcos-Cuevas, Julkunen, and Gabrielsson and Munksgaard, Johnsen, and Patterson regard aspirations for joint goals and goal congruence as influential in determining the effects of power. Even in asymmetric conditions, power can be mediated through the alignment of the parties’ goals. Marcos-Cuevas, Julkunen, and Gabrielsson posit that goal congruence mediates relationships, whether symmetrical or asymmetrical, such that congruence is a prerequisite of trust in either condition. Again citing their concept of soft power, in conditions in which trust is important, Von Bockhaven, Mathyssens, and Vandenbempt note the possibility of nuanced outcomes in asymmetrical relationships. That is, when interfirm parties' interests align, trust can be built and maintained, and the effects of power may be less prevalent, even if one party holds sway.

\section{3. $\quad$ Measuring and modelling power}

As Cowan, Paswan and Steenburg point out, most views of power in business contexts treat it as "a bad thing” and recommend interfirm exchanges that take place between equal, sharing, dyadic, or channel partners in a non-coercive environment. A contrary view holds that asymmetry and unequal spoils are the norm (Batt, 2004; Hingley, 2005a). Other authors argue that power should be central to any study of interfirm relationships (Cox, Sanderson, Watson, \& Lonsdale, 2001). According to Cowan, Paswan, and Steenburg though, the detail and nuances that are apparent in power measurements for (asymmetrical) business relations remain less clear. 
Some research has modelled the nature of power, such as in Cox et al.'s (2001) power regimes. Cox (2004) takes the buyer's perspective and suggests that the most appropriate way for a supplier to manage commercial transactions with buyers depends on its power and leverage circumstances. With a better understanding of the changing roles between buyers and suppliers, sales/procurement strategies could produce better rewards in the future. Cox (2001) also models the attributes of buyer and supplier power and suggests that relationships may be governed by their position on a matrix, in which quadrants signal buyer dominance, interdependence, independence, or supplier dominance. We again note a caveat identified by Hingley (2005b), namely, that there is inter- and intra-firm fluidity across the four cells of the matrix, so firms can reposition themselves or be repositioned by environmental and exchange circumstances. To further this model of power, Cowan, Paswan, and Steenburg seek to move beyond naming the parts of relationships, and propose a conceptual framework of relationships as exploitative, tolerable, ideal, or awkward. Chicksand also refers to Cox's work to re-raise the issue of the effect of power on partnerships.

Some commentators view partnerships as higher forms of relationships, modelled as advanced levels of interfirm integration (e.g., Webster, 1992). Mohr and Spekman (1994) believe partnerships are possible if compatible goals exist, along with mutual benefits and interdependence. However, the term suffers from a "woolly" definition and some interchangability with other terms (e.g., alliance), as well as an implied equality between partners, even if it does not exist in reality. In some ways, partnership exemplifies the ideal relationship described by Cowan, Paswan, and Steenburg, though the term begs questions in the same way that 'ideal' relationships do. That is, it exudes the same uneasy vision of higher-level perfection, grounded in theoretical, attribute-driven analysis. Neither term takes into full account the ability of power (and power plays) to intervene. Chicksand brings necessary focus to the issue by noting that though Cox extensively identifies and categorizes 
interfirm relationships and power, the prior work does not address how to measure it. Considering the cost and effort that exchange parties must invest to achieve higher relationship forms, including partnerships, it would be useful to learn how they can be shaped and maintained for long-term effectiveness. Chicksand thus concludes empirically that even when organizations lack compatible goals, mutual benefits, or interdependence, they might be called partnerships. In their empirical work, Marcos-Cuevas, Julkunen, and Gabrielsson similarly find that a supposed partner or symmetrical organization does not necessarily embrace aligned goals. Asymmetrical relationships instead might be more workable, whereas symmetrical ones may be at risk, due to a lack of engagement or complacency. Chicksand argues that if it is possible to understand where organizations stand with respect to one another on Cox's power matrix (he offers some identifiable relationship measurement methods), and some consciousness of the potential for overlapping, indiscernible power positions remains, then the possibility of a partnership is more identifiable within the boundaries of the effects of power.

\subsection{Power, intrafirm, and interfirm relationships}

Academic investigations of power in interfirm relationships feature a prevalence of dyadic studies. Munksgaard, Johnsen, and Patterson; Chicksand; and Palmer, Simmons, Robinson, and Fearne give due regard to the work of the interactionist IMP Group (1982), which offers an additional network orientation for power work, yet dyadic customer-supplier relationships remain the mainstay (e.g., Anderson, Hakansson, \& Johansson, 1994; Dwyer, Schurr, \& Oh, 1987). The dominance of dyadic studies spans from the previously cited work of Cox and Hingley to investigations by Narayandras and Rangan (2004) in the automotive industry and O’Keefe and Fearne (2002) in grocery retailer relationships.

Two-part exchanges are more accessible and perhaps replicable than studies of power that feature multiple tiers of interfirm relations or the even greater complexity of power in 
networks. However, such a focus begs the question: Have other organizational and infrastructural forms been neglected, such as triadic or multi-tier, horizontal (collaborative and cooperative), or intra-organizational relationships? As such, Najafi-Tavani, Zaefarian, Naudé, and Giroud concern themselves with subsidiary power, that is, how a subsidiary asserts power over its parent company. They contend that the key is the assertion of subsidiary autonomy and reverse knowledge transfer (e.g., research, sales, marketing data, systems, practical knowledge), to leverage its influence subtly at the head office. This assertion resonates with previous discussions about gradation and bolstering partners on the receiving end of asymmetric positions (e.g., Marcos-Cuevas, Julkunen, and Gabrielsson; Munksgaard, Johnsen, and Patterson; Cowan, Paswan, and Steenburg), as well as with the role of soft power in asymmetric positions (Von Bockhaven, Mathyssens, and Vandenbempt).

\subsection{Why is power considered so often in retailing and food supply relationships?}

It is not by design that this special issue features two sectors so heavily as topics for analysis. Specifically, six of the ten author groups in this special issue exhibit particular interest in investigating power in the interfirm relationships between retailers and suppliers and within food channels. Some of this interest might follow from the emphasis on research by Hingley and Cox, who also study food and retailing sectors; these sectors provide rich contexts for the study of power. For example, Maglaras, Bourlakis, and Fotopoulos investigate food retailing relationships to understand power imbalances, and they invoke the issue of the desirability of goal alignment (Marcos-Cuevas, Julkunen, and Gabrielsson; Munksgaard, Johnsen, and Patterson), recommending that individual organizations should develop supply chain-level goals that align the interests of different members and increase their compatibility, to create value for the overall chain (Gagalyuk, Hanf, \& Hingley, 2013). These authors acknowledge the weakness of retailer power-oriented supply chains for food suppliers, in terms of goal incompatibility (especially financial goals) with exchange partners, 
rather than retailer-led asymmetry. They also find that informational asymmetry, caused by a lack of knowledge sharing, reaffirms power imbalances. The heart of the issue again is trust (with information and data)—or the lack of it (as a cause of power issues). As Maglaras, Bourlakis, and Fotopoulos identify, this may be yet another reason food retailer supply chains are so popular for study: They show a marked shift in power, from supplier to retailer, in recent years (Fernie, 2014). Thus they demonstrate the prevalence of power dependence, such that asymmetry remains the reality in relationship exchanges (Hingley, 2005a).

Asymmetry can be viewed simply as a means of effective coordination, integration, and goal attainment (Belaya \& Hanf, 2009). What is interesting in this context is the possibility of gradation and modification of asymmetry, using goal alignment and trust-based exchanges. The study of interfirm relationships and power may be so prevalent in supplierretailer settings because, in asymmetric exchange conditions, retailers set the rules of the game in the form of general terms and conditions of trade. This is not unusual in exchange relationships; one party sets product, service, and quality specifications, for example. However, in grocery retailing, the power shift to the party that is nearest the end user offers the potential for some interesting observations. Rindt and Mouzas consider the German grocery sector, investigating how more powerful parties (retailers) use private rules (nonlegal sanctions) in asymmetric relationships to exercise their power. Retailers enforce trading and business conditions, using sanctions and interventions that institutionalize power asymmetries. The use of the private rules (e.g., product quality, service delivery) enforces power dependency. It is thus no coincidence that retailing, particularly for food and grocery items, has moved strongly into private label goods, produced solely for the retailer and bearing signals of its identity. In such conditions, the retailer has brand control over the supplier, and private rules enforce dependency in private-label supply. Rindt and Mouzas further illustrate the significance of outsourcing policies, not just for control over brand 
production but in service delivery as well (e.g., from outsourced research and development to entire supply chain management), which offsets the risk for retailers. Furthermore, the process of retailer-led reductions in supply chain members and the development of “preferred” suppliers (Collins \& Burt, 2003; Hingley, 2005a) have made large business accounts much more important to retail suppliers, invoking accentuated asymmetry in favour of the buyer.

An "enforcement, sanction, intervention" approach leaves open the possibility of punitive action and thus institutionalizes power asymmetry. For grocery retailing, such an asymmetric model is common and successful. Rindt and Mouzas show that suppliers' need to satisfy private rules also requires them to take responsibility for legislative rules (e.g., public health, food adulteration), but by outsourcing responsibility for these requirements through private rules, the more powerful parties (i.e., retailers) gain a further means for asymmetric control. Rindt and Mouzas therefore demonstrate that when the rules of the exchange are controlled by the stronger party and adapted as it sees fit, asymmetry gets reinforced, and the dilution that might be achieved by goal congruence becomes less possible. Evolving business conditions continue to be the norm for European and global food supply chains, especially in the wake of a series of scandals surrounding food contamination. Ultimately, retailers suffer from the negative publicity surrounding such high-profile events, but if they use private rules as sanctions, they can shrug off some of the responsibility to their providers, which mitigates their risk. This scenario also reinforces asymmetric power. In response, the general sense of inequity among government agents and even consumers has prompted some state intervention. For example, the United Kingdom recently addressed the largely unregulated world of privately controlled retailer food supply chain relationships by appointing a Groceries Code Adjudicator to sit in independent judgment on complaints from suppliers about their treatment from retail buyers, abuses of power, or unfair practices (Groceries Code 
Adjudicator, 2015). It will be interesting to see if such political intervention has an impact, beyond that exerted by public scrutiny and sanctions of power inequities in this sector, or if instead the better option for suppliers would be managed asymmetry (e.g., goal alignment).

Finally, in the grocery sector, considerable studies investigate and model dyadic exchanges, but we lack knowledge and understanding of the operation and maintenance of power in asymmetry, from the perspective of practitioners involved in it. Personalized accounts of how business exchanges operate are uncommon; where there is inequity, exchange partners are less inclined to talk about it, perhaps for fear of sanctions. Such investigations thus are rare, with minimal academic considerations of inequity in business exchange (e.g., Hornibrook, Fearne, \& Lazzarin, 2009). Palmer, Simmons, Robinson, and Fearne adopt an ethnographic approach to understand the daily operations of power for grocery retailers, bringing together suppliers and buyers from dominant retailer organizations in workshops. With this inside view, they determine how the management of institutional maintenance helps preserve power. This empirical study reveals the conditions of business life lived in asymmetry, through a close analysis of power dynamics from the perspective of the actual protagonists, as well as power plays associated with hard and soft power that retailers use to legitimize the kind of sanctions that Rindt and Mouzas describe. However, the process of perceiving power in relational exchanges from the viewpoint of respondents on both sides suggests the potential mitigation of power (through goal alignment). Regardless of the level of power imbalance in the relationship, if "insider views" can reveal the nature of the power dynamic, then weaker parties can at least understand and potentially realign themselves to achieve more manageable, beneficial conditions within the asymmetry.

\section{Directions for research and for power}

Najafi-Tavani, Zaefarian, Naudé, and Giroud make an important departure in the study of power in business relations; it is easy to identify other useful intra-firm replications 
that could contribute to internal power debates, perhaps even across the different sites, departments, or functions of a business, where extensive intra-organizational power plays take place. Important investigations might address issues of power between bureaucratic and operational functions, marketing and purchasing, or marketing and operations. Another avenue could be opened by Internet and online exchanges. In their contribution, Fukawa and Zhang examine the current challenges of power by exploring the use of non-coercive power in an open-source (web-accessed) context. Evidence of asymmetric relationships arises, such that strong, branded technology sector players (e.g., Google Android) take the lead, but they do not prevent gains by technology partners that use (according to profit-sharing agreements) the open source material available from these technology giants.

\section{Concluding remarks}

In this summary of the special edition on power in business, customer, and market relationships, we solicit the antecedents of power in business markets and draw out themes from the compendium of published articles in this issue. Thus, we have identified some important insights regarding the current state and future conceptualization of power in industrial markets. Most notably, we highlight a common theme about the nature of symmetry and asymmetry in interfirm relations: What was once idealized, namely, a symmetrical partnership, might be less than ideal. Equivalence and balance in exchanges have downsides, such as a lack of incentive or congruence. The most interesting outcomes stem from asymmetry. Furthermore, the seemingly negative conditions of asymmetry may contain positive attributes. In imbalanced relationships, gradations of asymmetry exist, and the possibilities of trust-based exchange belie the apparent imbalance, such that they might facilitate longer-term exchanges marked by goal congruence and trust.

In analyzing the recent history of academic thought in industrial marketing (through an appraisal of the content of power articles in $I M M$ ), we note a predominance of theoretical 
analyses related to interfirm, dyadic exchanges, with empirical investigations of the same, as well as a disproportionate interest in food chain and retailing power issues and illustrations. We would welcome further theoretical explorations and interpretations in other sectors, especially in efforts to meet the new business challenges posed by high technology, online, and virtual relationships and their consequent power issues. In terms of theory, we believe that there is still a gap with respect to causal research and welcome further experimentation concerning power, and perhaps investigation using longitudinal methods. Finally, we note a gap in multitier, multinational, network, and intra-organizational studies with respect to understanding and achieving the empirical application of power in industrial business, customer, and market relationships.

\section{References}

Anderson, J.C., Håkansson, H., \& Johansson, J. (1994), "Dyadic business relationships within a business network context,” Journal of Marketing, 58, 1-15.

Batt, P.J. (2004), “Power-dependence in agricultural supply chains: Fact or fallacy?” in Proceedings of 20th Annual Conference of the Industrial Marketing and Purchasing Group, Copenhagen, 2-4 September.

Belaya, V., \& Hanf, J. H. (2009), "The two sides of power in business-to-business relationships: implications for supply chains,” Marketing Review, 9(4), 361-381.

Blois, K. J. (2005), “Self-interest and not benign power-a comment on Hingley’s 'Power to all our friends',” Industrial Marketing Management, 34(8), 859-862.

Collins, A., \& Burt, S. (2003), "Market sanctions, monitoring and vertical coordination within retailer-manufacturer relationships: The case of retail brand suppliers,” European Journal of Marketing, 37 (5/6), 668-689.

Cox, A. (1999), “Power, value and supply chain management,” Supply Chain Management, 4 (4), 167-175. 
Cox, A. (2001), “The power perspective in procurement and supply management,” Journal of Supply Chain Management, 37 (2), 4-7.

Cox, A. (2004), “The art of the possible: Relationship management in power regimes and supply chains,” Supply Chain Management, 9 (5), 346-56.

Cox, A., \& Chicksand, D. (2005), “The limits of lean management thinking: Multiple retailers and food and farming supply chains,” European Management Journal, 23(6), 648-662.

Cox, A., Sanderson, J., Watson, G., \& Lonsdale, C. (2001), "Power regimes: A strategic perspective on the management of business-to-business relationships in supply networks.” In H. Håkansson, C. A. Solberg, L. Huemer, \& L. Steigum (eds.), Proceedings of the 17th Annual IMP Conference: Interactions, Relationships and Networks: Strategic Dimensions, Oslo: Norwegian School of Management BI, 9-11 September.

Dwyer, F. R., Schurr, P. H., \& Oh, S. (1987), "Developing buyer-seller relationships," Journal of Marketing, 51 (April), 11-27.

Easton, G. (2002), “Marketing: a critical realist approach,” Journal of Business Research, 55, (2), 103-109.

Emerson, R. M. (1962), “Power dependence relations,” American Sociological Review, 27(1), $31-41$

Fernie, J. (2014), “Relationships in the supply chain,” In J. Fernie \& L. Sparks (Ed.), Logistics and retail management: Emerging issues and new challenges in the retail supply chain (pp. 35-58). London: Kogan Page.

French, R. P., \& Raven, B. (1959), “The bases of social power,” In D. Cartwright (Ed.), Studies in social power (pp. 155-164). Ann Arbor, MI: University of Michigan Press. 
Ganesan, S. (1994), “Determination of long-term orientation in buyer-seller relationships', Journal of Marketing, 58, 1-19.

Geyskens, I., Steencamp, J-B.E.M., Scheer, L.K. \& Kumar, N. (1996), “The effects of trust and interdependence on relationship commitment: A transatlantic study”, International Journal of Research in Marketing, 13, 303-317.

Gagalyuk, T., Hanf, J. H., \& Hingley, M. (2013), “Firm and whole chain success: network management in the Ukrainian food industry,” Journal of Network and Chain Science, 13(1), 47-70.

Groceries Code Adjudicator (2015). www.gov.uk/government/organisations/groceries-codeadjudicator. [accessed online 2/3/15].

Hingley, M. (2005a), "Power to all our friends? Living with imbalance in supplier-retailer relationships,” Industrial Marketing Management, 34 (8), 848-858.

Hingley, M. (2005b), "Response to comments on 'Power to all our friends/ living with imbalance in UK supplier-retailer relationships,,” Industrial Marketing Management, 34 (8), 870-875.

Hingley, M., \& Lindgreen, A. (2010), "Living with power imbalance in the food supply chain,” in C. Mena \& G. Stevens (Eds.), Delivering performance in food supply chains (pp. 37-57). Cambridge: Woodhead Publishing Ltd.

Hornibrook, S. A., Fearne, A., \& Lazzarin, M. (2009), “Exploring the association between fairness and organisational outcomes in supply chain relationships,” International Journal of Retail and Distribution Management, 37 (9), 790-803.

IMP Group (1982). International marketing and purchasing of industrial goods: an interaction approach. Chichester: Wiley.

Johnsen, R. E. \& Ford, D. (2006), ”Interaction capability development of smaller suppliers in relationships with larger customers,” Industrial Marketing Management, 35 (8), 10021015. 
Johnsen, R. E. \& Ford, D. (2008), "Exploring the concept of asymmetry: a typology for analysing customer-supplier relationships,” Industrial Marketing Management, 37 (4), 471-483.

Kumar, N. (2005), “The power of power supplier-retailer relationships,” Industrial Marketing Management, 34 (8), 863-866.

Mohr, J., \& Spekman, R. (1994), “Characteristics of partnership success: partnership attributes, communication behavior, and conflict resolution techniques,” Strategic Management Journal, 15(2), 135-152.

Naudé, P. (2005), “Comments on 'Power to all our friends? Living with imbalance in supplier-retailer relationships’ by Martin Hingley,” Industrial Marketing Management, 34 (8), 867-869.

Narayandras, D. \& Rangan, V.K. (2004), ”Building and sustaining buyer-seller relationships in mature industrial markets,” Journal of Marketing, 68 (3), 63-7.

O’Keefe, M., \& Fearne, A. (2002), “From commodity marketing to category management: Insights from the Waitrose category leadership programme in fresh produce,” Supply Chain Management, 7 (5), 296-301.

Ramsay, J. (1996), “The case against purchasing partnerships,” International Journal of Purchasing and Materials Management, (Fall), 13-21.

Thibaut, J. W., \& Kelley, H. H. (1959). The social psychology of groups. New York: Wiley.

Webster, F.E. (1992), “The changing role of marketing in the corporation,” Journal of Marketing, 56 (3), 1-17.

Yeung, J. H. Y., Selen, W., Zhang, M., \& Huo, B. (2009), ”The effects of trust and coercive power on supplier integration,” International Journal of Production Economics, 120(1), 66-78. 